\title{
The Role of Games in Special Preschool Education
}

\author{
https://doi.org/10.3991/ijet.v11i12.5945 \\ Georgia K. Kokkalia ${ }^{1}$ Athanasios S. Drigas ${ }^{1}$, \& Alexandra Economou ${ }^{2}$ \\ ${ }^{1}$ NCSR DEMOKRITOS, Institute of Informatics and Telecommunications, Net Media Lab, Athens, Greece \\ ${ }^{2}$ Department of Psychology, University of Athens, Athens, Greece
}

\begin{abstract}
Recent development in new technology has led many teachers, schools and other educators to use it with their students in their learning process. Especially, in the field of special preschool education the role of educational computer games seem significant. In this short review paper we give a brief overview of the most representative articles that concentrate on these games that support preschool children who face literature, math, cognitive, intellectual and physical difficulties. The role of computer educational games in children who are gifted or face developmental disorders (autism) is also explored.
\end{abstract}

Index Terms-games, interventions, preschool, special education

\section{INTRODUCTION}

Various research groups, including state and national organizations, are trying to explore the impact of using new technology in learning of kindergarten children [1] Many resources have been dedicated to equip teachers, as they attempt to integrate a variety of digital technologies into their classrooms while the recent outcry for ubiquitous computing has led to a focus on handheld devices in schools [2]. Handheld devices in kindergarten education have evolved from Palm Pilots and PDA's (Personal Digital Assistant) in the past decade [3] to cell phones and MP3 players more recently [4].

In the past decade, many studies were conducted to investigate the effectiveness of educational computer games for various courses, such as mathematics software engineering business, computer science, geography, language and decision- science. More specifically, previous studies have reported that educational computer games can enhance the learning interest of children, and also increase their learning motivation. Researchers have also stated that games play a significant part of the development of children's cognition and social processes [5] while they may improve their learning performance as well as their learning motivation [6]. Taking the above into account it is notable to say that Kinzie and Joseph [7] indicated, that a game is thought as an immersive, voluntary and enjoyable activity in which a challenging goal is pursued according to agreed rules and owing to the rapid advancement and popularity of computer and communication technologies, researchers have supported the view that educational computer games could play an important role in education [8]. In addition, the idea of games as mean of offering knowledge has been around for some time and is usually referred as serious games. This initiative, known as serious games, has changed the way that educators viewed instruction to meet the needs of the children and serious games have impacted the military and firefighters, the medical and higher business education as well as the mainstream and special education [9].

Furthermore, recent studies state that young children ages 3 to 6 (preschoolers) play a wide range of serious games, which are now available on large screens, handheld screens, electronic learning systems, and electronic toys, and their time spent with games is growing. A small body of research has found that games-when well designed - can provide rich, fun, interactive experiences that can foster young children's learning, cognitive development, skill building, social interactions, physical activity, and healthy behaviors [10].

However, a specific sensitive and crucial area of games and education is the special preschool education and the role of games in it. Pre-school children's learning disabilities include biological/genetic disorders, perceptualmotor disorders, and visual processing disorders. In other words, neuropsychological learning disabilities are related to pre-school skills groups that the child requires for learning. One of problems of pre-school children with neuropsychological/developmental disabilities is executive functions and attention that involves abilities needed by children to learn school lessons. Observed characteristics in these children are delayed motor development, language delays, speech disorders, poor cognitive and conceptual development [11]. In this article review we will try to present briefly some of the most notable studies on serious games in preschool education according to the educational perspective. Specifically we will try to show how games can help children who face literature, math, motor, communicational, cognitive and emotional difficulties. Moreover, we will try to investigate the games that are used for children with autism and ADHD and examine the games that help gifted and talented preschoolers.

\section{SUPPORTING CHILDREN With LITERACY DIFFICULTIES}

The diagnosis and the assessment of learning disabilities is often determined when children begin to exhibit academic difficulties in school, and the average age when children receive learning disabilities assessments is 9years [12]. Delayed intervention can result in adverse and persistent consequences for academic skill acquisition. In contrast, early identification of children at risk for learning disabilities may offer the potential to mitigate the negative effects of delayed intervention by directing children to preventive services at an earlier age [13].

Young children with disabilities often have difficulties developing emergent literacy skills as phonological 
awareness, alphabetic principles, comprehension, concepts about print, and vocabulary development [14]. The National Reading Panel [15] found that instruction in phonological awareness significantly improves children's reading abilities. PowerPointTM has many features to facilitate acquisition of these skills, including the ability of the teacher to modify such features as color, pictures, sounds, animation, slide design, and slide transition. As a result, educators can help young children develop initial sound fluency by making them aware of words that start with the same sound, or alliterations [16]. Furthermore, phonemic orthography that has to do with the relationships between letters and their associated sounds [17] can be taught with the connection between a letter and its associated sound. PowerPointTM activities can be constructed to help young children develop letter-sound correspondence. The teacher might use the animation features to control the appearance of each letter in a word so that it is isolated, and can be linked with the sound that corresponds to it. Such a PowerPointTM strategy could further help students learn about the blending of sounds and how letters connect with sounds in various words.

Moreover, dyslexia which is one of the main learning disabilities affecting the reading acquisition and thus is of crucial importance to obtain early diagnosis is diagnosed not earlier than primary school as difficulties in reading is used as first indicator. Yet, being able to detect and treat this problem even in preschool years would ensure better chances to limit its impact and help the child's future reading ability. To this aim a research team designed a series of serious games to train specific skills that have been proven to be effective against dyslexia. Specifically in this study a system composed by various serious games designed for predicting the risk of developing dyslexia in very young children training also phonological skills and the visual-spatial attention, which are usually impaired in these children, in order to improve their future reading ability. The results of the study that are encouraging show that such serious games can be used as daily treatment with a low probability of drop out allowing a discrimination between children with a high risk of dyslexia and other children, based on the players' performance [18].

\section{Supporting CHILDERN With MATH DifFiculties}

Developmental dyscalculia is a disorder in mathematical abilities presumed to be due to a specific impairment in brain function and is highly similar to legal definitions of mathematical disabilities. However although the theoretical definition of these constructs is generally agreed upon, their operalization is another issue, and varying selection criteria have tended to result in considerable differences between the populations in different studies as much remains to be discovered about the symptoms of dyscalculia [19]. 'The Number Race"' is an adaptive game designed to improve number sense [20]. Like adaptive games in literacy this software was designed as a remediation tool for learning disabilities, but may also be useful in other populations associated with low number sense, such as children with low socioeconomic status. Its effectiveness was checked using a crossover design in 53 low socioeconomic status kindergarteners in France. The findings showed that children had improvements in tasks that had to do with number sense and more specifically with numerical comparison of digits and words. Additionally, children can use it with minimal supervision, making it suitable for home or classroom use while its instructional principles behind "The Number Race" were based on research in numerical cognition (number sense, links between non-symbolic and symbolic representations of number; and understanding of addition and subtraction facts).

Additionally, it has been documented that educational games could function as effective and engaging teaching tools in promoting early number sense development [21]. In a previous study, Young-Loveridge [22] found teaching a group of low achieving 5-year-olds using commercial number books and games for 30 minutes a day for 7 weeks significantly improved their numeracy ability compared to the contrast group. The effect diminished with time after the intervention ceased but remained significant after a year.

Another well implemented randomized controlled study by Ramani and Siegler [23] found that playing number board games improved numeracy skills of low-income preschoolers. The study included preschool children from 10 urban Head Start centers. Seventy-two children were randomly selected to play a number board game with a trained experimenter while the other 64 played a different version of the same game using colors instead of numbers. The game included a liner number board with numbered squares, two game pieces, and spinner. Players took turns spinning and moving the game pieces around the board. They read numbers from the board aloud while moving game pieces. Each child completed 4 game sessions for 15 to 20 minutes each over a 2 -week period. The results showed that at the end of the 2-week period, children who played the number game had better counting and number identification skills than those who played the color game and were also better at picking the higher number from a pair and estimating positions on a number line.

\section{SupPorTING CHILDREN WITH ADHD}

In the area of childhood attention-deficit hyperactivity disorder, there is an urgent need for new, innovative, and child-focused treatments. Children with ADHD are hyperactive and impulsive and have difficulty concentrating, planning, and organizing their daily activities. These characteristics disturb their learning and achievement at school and causes problems to their social interactions with the family and their peers. As a result all these may have a negative impact on the children's self-image and selfconfidence as ADHD is one of the most frequently diagnosed disorder in school children under 16 years and is more common in boys that in girls [24].

Taking the above into consideration, a computerized executive functioning training, called "Braingame Brian", with game elements aimed at enhancing self-control, was designed. "Braingame Brian" meets the need for a new, child-focused treatment for ADHD as it is the first program that trains three executive functions (working memory, inhibition and cognitive flexibility) at the same time and uses game elements in the training. The first results seem promising, while the future steps involve replication with larger samples, evaluating transfer of training effects to daily life, and enhancing motivation through more gaming elements [25].

Furthermore, the most researched approach, that is thought successful, is CogMed a computerized workingmemory training that uses computer games that progres- 
PAPER

sively increase working-memory demands. Young children may improve on games they practice, their workingmemory tasks while many improvements may be shown on children with ADHD with poor working-memory spans [26].

In addition, video game therapy for children with ADHD has attracted a large amount of scholarly attention, because many children who do not inhibit their hyperactivity in other contexts will do so when playing intrinsically motivating video games. Lawrence et al. [27] highlighted that 6-12-year-old boys with ADHD perform beneath a normally developing control group when playing a cognitively demanding adventure video game, and even more so on a route task outside the laboratory, but perform equally well on a motor-skill targeting game that does not involve high working memory or distractor loads. According to them, this engagement makes video games ripe for therapeutic applications.

\section{Supporting CHILDREN With AUTISM}

During the last years there is considerable advance in the research on innovative computer technologies for the education of people with Autistic Spectrum Disorder. The specialists and educators are aided by interactive environments in facing the daily abnormal reactions by autistic children that can generally be classified as problematic social interaction, communication impairment dealing with verbal and non-verbal use of the language [28].

Various interactive environments have been designed for helping children with autism and in most of the cases these environments are software-educating platforms. In order to provide knowledge in an attractive way, these platforms use entertaining content in educational settings. The games usually use photos of daily life or sketches in order to encourage children with autism to distinguish objects based on their basic characteristics. Specifically these kinds of interactive learning platforms motivate the children to correlate the objects with sounds and words [29].

Additionally, robotic systems are often included in the interactive environments. Developed as interactive toys for children, humanoid robots are used as research platforms for studying how a human can teach a robot, using imitation, speech and gestures. Increasingly, robotic platforms are developed as interactive playmates for children. Recent literature reveals that robots generate a high degree of motivation and engagement in autistic persons, including those who are unlikely or unwilling to interact socially with human educators and therapists [30].

Moreover, Jowett EL [31] evaluated the effectiveness of a video-modeling package to teach a preschool child diagnosed with autism basic numeracy skills. The intervention consisted of iPad-based video modeling, gradual fading of video prompts, reinforcement, in vivo prompting and forward chaining. The developers showed that at the end of the intervention the child could identify and write the Arabic numerals 1-7 and understand the quantity each numeral represents in association with the lagged intervention. Lastly, this study confirmed that iPad-based video modeling, when used as the above intervention, could be an effective technique for teaching numerical skills to children with autism.

Recently, Serret [32] developed a serious game, "Jestimule", to improve social cognition in autistic children.
The designers tried to develop the game with consideration for the heterogeneity of autism and thus new technology was used to facilitate the use of the game by young children or by children with developmental delays. They also evaluated the serious game for its effectiveness in teaching the autistic children to recognize facial emotions, emotional gestures and emotional situations. The results of the study showed that the children who used "Jestimule" could play and understand the serious game even when they had intellectual disabilities. They also showed that participants improved their recognition of facial emotions, emotional gestures and emotional situations in different tasks. These preliminary results have clear education and therapeutic implications in this disorder and should be taken into account in future training.

\section{SUPPORTING CHILDREN WITH INTELLECTUAL AND PHYSICAL DISABILITIES}

Students with Intellectual Disability (ID) are often described as "slow learners" and cannot easily follow the normal curriculum. In other words the needs of a person with ID for accomplishment, enjoyment and perception of high quality multimedia content are augmented. In general education settings serious games for learning seem to work successful with students regardless of their developmental state. However, if this approach is suitable and effective for students with ID, this is a subject of investigation and consideration [33].

However, according to some researchers, there are games that seem effective and successful for children with such difficulties. More specifically, in games such as Sebran and All About Numbers children with ID visualize grammatical, vocabulary and mathematical concepts with colorful pictures and animations. Additionally, Alphabet Track gives children the opportunity to move through eight fun activities at their own pace. As a result, children learn to recognize and locate letters of the alphabet quickly and consistently acquiring more spelling independence. Moreover, Toward Independence is a well-rounded collection of five life- skill programs/games that covers basic vocabulary and community outings, money skills, shopping and social behavior [34].

Moreover, Cameirao, et al [35] stated that videogames, involving the sensory-motor system and problem solving skills are more than serious candidates for neuroehabilitation and motor or cognitive training. Additionally, identified several improvements in gaming activity, from reaction times to spatial skills, and noted the chances to use this kind of media to improve cognitive functions in individuals with particular needs as young children with special health-related problems or young disabled [36].

Furthermore, commercial gaming technology is now focusing on physical interactivity, as in the control system of Nintendo DS ${ }^{\circledR}$, and Nintendo Wii ${ }^{\circledR}$, which involves the whole body in the game activity. Both of these applications allow the manipulation of virtual objects on the screen, through the performance of intuitive gestures handling real tools [37]. These potentialities have inspired some interesting projects as Pearson and Bailey [38] who proposed to analyze the effects of this console system in supporting learning processes in cognitively and physically disabled people. The physical nature of interaction can be particularly appealing for these individuals, facilitating their acceptance of computer-mediated learning programs helping as well children with problems like apraxia. 
Last but not least, Lumbreras and Sanchez [39] developed a 3D audio Virtual Game named AudioDOOM for blind children. The child is asked to handle a joystick to explore a maze following 3D audio cues and finding enemies. After several sessions, participants showed to be able to reproduce a physical representation of the maze using Lego bricks. As a result of the above findings the Swedish Library of Talking Books and Braille proposed a series of 13 computer games on their web site, specially designed for children with different visual impairments. Specifically, the games were small Macromedia FlashTM applications, designed using graphics and sound in order to encourage children with visual impairments to exercise visual objects recognition, and to create picture-based and sound-based games [40].

\section{SUPPORTING GIFTED CHILDREN}

Preschool gifted education is arguably the most neglected area in education. According to Barbour and Shaklee [41] gifted children 0 to 8 years of age are among the most underserved children, even though early intervention has a significant effect on their continued development. This neglect is likely the case for two reasons. First, while public funding for preschool gifted programs is non- existent and second the wrong view that gifted students do not require special support services because they will flourish under any and all circumstances [42]. Experts in gifted education disagree with this opinion as the early intervention makes a significant difference in a young gifted child's social and intellectual development [42].

In recent years new technology has become a common instructional method used with gifted and talented learners. It can be used to enhance and replace existing educational methods and to improve education for the gifted student. This same information technology can also be used to design an appropriate learning environment that allows for enriched learning experiences and more advanced study for these high-ability children [43].

In the light of the above statements, teachers may enhance learning concepts using online learning games as many talented students enjoy stimulating and challenging activities [44]. Teachers can find games titled Math Bingo and Wacky Wordplay at Education World's Online Game Archives or subject-area action games at About.com (http://homeschooling.about.com/ od/games). Online learning games can be used to reinforce concepts in many different areas according to children's interest [45].

In addition, according to a recent study internet-based information and communication technology (ICT) can assist in registering, integrating, evaluating, and reporting instructional, learning, and evaluation processes in various ways gifted children in kindergarten. Mooij [46] also developed a psychometrically controlled screening game for both parents and teachers-that estimates a child's level by comparing the child's behaviour with the behaviour of same-age peers. The results can be used to check and compare the parents' and kindergarten teachers' views of the child as well as to collect and design the appropriate play materials or instructional lines according to child's level.

Lastly, Cukierkorn et al [47] suggest that gifted children should synthesize their learning, proposing that children's work may be scanned and placed into a PowerPoint presentation, allowing the child to choose slide design styles, create slide titles, and add text. They continue saying that these presentations can then be shared with other students and parents or published on the Web. This action can be useful because gifted children can improve their skills and feel comfortable when they exchange information with each other.

\section{CONCLUSIONS}

As it has been discussed in this short review article educational games have a rich potential to incorporate the instructional content and methodologies required for preschool children with developmental and other disabilities. A number of games for different educational fields was presented and many considerations were presented. The fields of learning difficulties and developmental disorders as well the field of talented and gifted children were explored talking into consideration the needs of these children.

However it is our view that the integration of serious games in the kindergarten classroom is more of a matter of attitude rather than a question of appropriate game design. According to the researchers, educators need to rebuild their faith in gaming, become familiar with digital gaming and assimilate a medium that promises to reveal the hidden potential of their children.

In addition, game researchers and the game industry need to understand the possibilities of educational games and create games that are able to flourish learning. The limits of time, resources as well as the requirements of curriculum and individual instructional needs should clearly be taken into consideration, especially with respect to preschoolers with intellectual or other disabilities.

The educational sector and the game industry need to be cooperated in order to offer the best and more appropriate results in education of preschoolers who face difficulties. Despite of the above findings of our research we have to mention the need of more attention and research on the domain of special education. The new generation and the demand of new society seem more demanding and thus the need of more educational games is necessary.

\section{REFERENCES}

[1] Swain, C., \& Pearson, T. : Educators and technology standards: Influencing the digital divide. Journal of Research on Technology in Education, pp. 326-335 (2002) https://doi.org/10.1080/1539 1523.2002.10782353

[2] Alexander, B.: Going nomadic: Mobile learning in higher education. Educause Review, 35(5), pp. 29-35 (2004)

[3] Baumbach, D., Christopher, T., Fasimpaur, K., \& Oliver, K.: Personal assistants literacy using handhelds for literacy instruction. Learning and Leading with Technology, pp. 16-21 (2004)

[4] Bomar, L.: iPods as reading tools. Principal, pp. 52-53 (2006)

[5] Yien, J. M., Hung, C. M., Hwang, G. J. \& Lin, Y. C. : A gamebased learning approach to improving students' learning achievements in a nutrition course. Turkish Online Journal of Educational Technology, pp. 1-10 (2011)

[6] Huang, W. H., Huang, W. Y. \& Tschopp, J. : Sustaining iterative game playing processes in DGBL: the relationship between motivational processing and outcome processing. Computers \& Education, pp. 789-797 (2010) https://doi.org/10.1016/j.compedu.2010. 03.011

[7] Kinzie, M. B. \& Joseph, D. R. D.: Gender differences in game activity preferences of middle school children: implications for educational game design. Educational Technology Research \& Development, pp. 643-663 (2008) https://doi.org/10.1007/s11423$\underline{007-9076-z}$ 
[8] Prensky, M. : Digital game-based learning. New York: McGraw Hill (2001)

[9] Fernández-Oliveras, A., \& Oliveras, M. L. (2015). Conceptions of science, mathematics, and education of prospective kindergarten teachers in a play-based training. International Journal on Advances in Education Research, 2(1), 37-48.

[10] Lieberman, D. A., Fisk, M. C., \& Biely, E.: Digital games for young children ages three to six: From research to design. Computers in the Schools, pp.299-313 (2009) https://doi.org/10.1080/ $\underline{07380560903360178}$

[11] Abedi, A, Malekpour, M., Moulavi, H., Oreyzi, S. S. B. R, \& Amiri, S.: Comparison of executive functions/attention of children with neuropsychological/developmental learning disabilities and normal children in preschool stage (2008)

[12] Shaywitz, S.E. : Current concepts: Dyslexia. New England Journal of Medicine, pp. 307-312(1998) https://doi.org/10.1056/NEJM19 9801293380507

[13] National Institutes of Health [NIH].: Emergent literacy workshop: Current status and research directions (2000)

[14] Cook, R. E., Klein, M. D., \& Chen, D. : Adapting early childhood curricula for children with special needs. Pearson Higher Ed (2011)

[15] National Reading Panel (US), National Institute of Child Health, \& Human Development (US). (2000). Report of the national reading panel: Teaching children to read: An evidence-based assessment of the scientific research literature on reading and its implications for reading instruction: Reports of the subgroups. National Institute of Child Health and Human Development, National Institutes of Health (2000)

[16] Parette, H. P., Hourcade, J. J., Boeckmann, N. M., \& Blum, C. (2008). Using Microsoft $\AA$ PowerPoint ${ }^{\mathrm{TM}}$ to support emergent literacy skill development for young children at-risk or who have disabilities. Early Childhood Education Journal, pp. 233-239 (2008) https://doi.org/10.1007/s10643-008-0275-y

[17] Hutinger, P. L., Bell, C., Daytner, G., \& Johanson, J.: Establishing and maintaining an early childhood emergent literacy technology curriculum. Journal of Special Education Technology, pp. 39 (2006)

[18] Gaggi, O., Galiazzo, G., Palazzi, C., Facoetti, A., \& Franceschini, S.: A serious game for predicting the risk of developmental dyslexia in pre-readers children. In Computer Communications and Networks (ICCCN), 2012 21st International Conference on IEEE pp. 1-5 (2012,July)

[19] Shalev, R. S.: Developmental dyscalculia. Journal of child neurology, pp. 765-771(2004)

[20] Wilson, A. J., Dehaene, S., Dubois, O., \& Fayol, M.: Effects of an Adaptive Game Intervention on Accessing Number Sense in LowSocioeconomic-Status Kindergarten Children. Mind, Brain, and Education, pp. 224-234 (2009) https://doi.org/10.1111/j.1751228X.2009.01075.x

[21] Baroody, A. J., Eiland, M., \& Thompson, B.: Fostering at-risk preschoolers' number sense. Early Education and Development, pp. 80-120 (2009) https://doi.org/10.1080/10409280802206619

[22] Young-Loveridge, J. (2004). Effects on early numeracy of two programs using number books and games. Early Childhood Research Quarterly, pp. 82-98(2004) https://doi.org/10.1016/j.ec resq.2004.01.001

[23] Ramani, G. B., \& Siegler, R. S.: Promoting broad and stable improvements in low-income children's numerical knowledge through playing number board games. Child Development, pp. 375-394 (2008) https://doi.org/10.1111/j.1467-8624.2007.01131.x

[24] Froehlich TE, Lanphear BP, Epstein JN : Prevalence, recognition, and treatment of attention-deficit/hyperactivity disorder in a national sample of US children. Arch Pediatr Adolesc Med 2007; 161pp. 857-864

[25] Prins, P. J., Brink, E. T., Dovis, S., Ponsioen, A., Geurts, H. M., De Vries, M., \& Van Der Oord, S. : "Braingame Brian": toward an executive function training program with game elements for children with ADHD and cognitive control problems. GAMES FOR HEALTH: Research, Development, and Clinical Applications, 2(1), 44-49(2008) https://doi.org/10.1089/g4h.2013.0004

[26] Shipstead, J., Hicks, K., Engle, R.: Cogmed Working Memory Training: Does the evidence support the claims? Journal of Ap- plied Research in Memory and Cognition 1,pp. 185-193 (2012) https://doi.org/10.1016/j.jarmac.2012.06.003

[27] Lawrence, V., Houghton, S., Tannock, R., Douglas, G., Durkin, K., \& Whiting, K. : ADHD outside the laboratory: Boys' executive function performance on tasks in videogame play and on a visit to the zoo. Journal of Abnormal Child Psychology, pp. 447-462 (2002) https://doi.org/10.1023/A:1019812829706

[28] Luneski, A., Konstantinidis, E. I., Hitoglou-Antoniadou, M., \& Bamidis, P. D. :Affective computer-aided learning for autistic children. In WOCCI p.7 (2008)

[29] Lányi, C. S., \& Tilinger, Á.: Multimedia and virtual reality in the rehabilitation of autistic children pp. 22-28, Springer Berlin Heidelberg (2004) https://doi.org/10.1007/978-3-540-27817-7_4

[30] Sutera, S., Pandey, J., Esser, E. L., Rosenthal, M. A., Wilson, L. B., Barton, M., ... \& Fein, D.: Predictors of optimal outcome in toddlers diagnosed with autism spectrum disorders. Journal of autism and developmental disorders, pp. 98-107 (2007) https://doi.org/10.1007/s10803-006-0340-6

[31] Jowett EL, Moore DW, A. A.: Using an ipad- based video modelling package to teach numeracy skills to a child with an autismspectrum disorder. Dev Neurorehabil, (2012) https://doi.org/10.3109/17518423.2012.682168

[32] Serret, S.: Jestimule, a serious game for autism spectrum disorders. Neuropsychiatrie de l' Enfance et de l' Adolescence, pp. 59 (2012) https://doi.org/10.1016/j.neurenf.2012.05.237

[33] De Freitas, S.: Using games and simulations for supporting learning. IN C. Martin \& L. Murray (Eds.), Learning, Media.and.Technology. Special.Issue.on.Gaming (2006)

[34] Saridaki, M., Gouscos, D., \& Meimaris, M.: Digital Games-Based Learning for Students with Intellectual Disability. Game-Based Learning Advancements for Multi-Sensory Human Computer Interfaces: Techniques and Effective Practices, Information Science Reference Publications (2009)

[35] Cameirao, M. S., Bermúdez i Badia, S., Duarte Oller, E., Zimmerli, L., \& Verschure, P. F. M. J. The Rehabilitation Gaming System: A virtual reality based system for the evaluation and rehabilitation of motor deficits. Proceedings of Virtual Rehabilitation, Venice, Italy (2007)

[36] Green, C. S., \& Bavelier, D.: Action video game experience alters the spatial resolution of attention. Psychological Science, pp. 8894(2007) https://doi.org/10.1111/j.1467-9280.2007.01853.x

[37] Gamberini, L., Barresi, G., Maier, A., \& Scarpetta, F.: A game a day keeps the doctor away: A short review of computer games in mental healthcare. Journal of CyberTherapy and Rehabilitation, pp. 127-145 (2008)

[38] Pearson, P. and Bailey, C. (2007). Evaluating the potential of the Nintendo Wii to support disabled students in education. Ascilite 2007, 2-5 December, Singapore

[39] Sánchez, J., \& Lumbreras, M.: Usability and cognitive impact of the interaction with 3D virtual interactive acoustic environments by blind children. In Medicine Meets Virtual Reality , (2000)

[40] Weiss, P. L., Rand, D., Katz, N., \& Kizony, R.: Video capture virtual reality as a flexible and effective rehabilitation tool. Journal of neuroengineering and rehabilitation, p. 12 (2004) https://doi.org/10.1186/1743-0003-1-12

[41] Barbour, N. E., \& Shalilee, B. D.: Gifted education meets Reggio Emilia: Visions for curriculum in gifted education for young children. Gifted Child Quarterly, 42(4), 228-237(1998) https://doi.org/10.1177/001698629804200406

[42] Chamberlin, S. A., \& Moon, S. M.: Model-eliciting activities as a tool to develop and identify creatively gifted mathematicians. Prufrock Journal, 17(1), 37-47 (2005)

[43] Wasserman, S. (2001): Curriculum enrichment with computer software: Adventures in the trade. Phi Delta Kappan, 82, pp. 592598 (2001) https://doi.org/10.1177/003172170108200809

[44] Westwater, A., \& Wolfe, P. (2000): The brain-compatible curriculum. Educational Leadership, pp. 49-52 (2000)

[45] Mulrine, C. F. (2007): Creating a Virtual Learning Environment for Gifted and Talented Learners. Gifted child today, pp. 37-40 (2007)

[46] Mooij, T.: Designing instruction and learning for cognitively gifted pupils in preschool and primary school. International Jour- 
nal of Inclusive Education 17(6), pp. 597-613 (2013) https://doi.org/10.1080/13603116.2012.696727

[47] Cukierkorn J., Karnes, F., Manning, S. Houston, H., Besnoy,K. Serving the preschool gifted child: Programming and resources. Roeper Review, 29(4), 271-276(2007) https://doi.org/10.1080/02 $\underline{783190709554422}$

\section{AUTHORS}

Athanasios Drigas is a Research Director at IIT, N.C.S.R. Demokritos. He is the Coordinator of Telecoms $\mathrm{Lab}$ and founder of Net Media Lab since 1996. From 1990 to 1999 he was the Operational manager of the Greek Academic network. He has been the Coordinator of Several International Projects, in the fields of ICTs, and eservices (e-learning, e-psychology, e-government, einclusion, e-culture etc). He has published more than 270 articles, 7 books, 25 educational CD-ROMs and several patents. He has been a member of several International committees for the design and coordination of Network and ICT activities and of international conferences and journals. Also he has accepted several distinctions for his work (articles, projects, patents) (e-mail: dr@iit.demokritos.gr).

Alexandra Economou is an assistant professor at the University of Athens in the department of Psychology. She teaches undergraduate and postgraduate neuropsychology and experimental psychology courses at the University of Athens in the Department of Psychology while her interests focus on cognitive and biological psychology. Dr. Economou is also vice-president of the Greek Aphasia Association. (E-mail: aoikono@psych.uoa.gr)

Georgia Kokkalia (MSc in Specific Learning Difficulties) is a Special Education Teaching Professional. She has participated in various research projects regarding the use of Information and Communication Technologies (ICTs) in Special Education and in Kindergarten. (e-mail: gioulina@hotmail.com).

Submitted 13 June 2016. Published as resubmitted by the authors 25 August 2016. 